\title{
PERSEPSI DUKUNGAN KELUARGA TERHADAP KELEKATAN IBU DAN JANIN
}

\author{
Nida Tsaura Sjariati, Linda Primana \\ ${ }^{1,2}$ Universitas Indonesia, \\ Kampus Baru UI Depok, Jawa Barat \\ E-mail: nida.tsaura@gmail.com
}

\begin{abstract}
ABSTRAK
Penelitian ini merupakan penelitian kuantitatif non-eksperimental dengan metode korelasional. Fenomena Angka Kematian Ibu (AKI) yang tinggi di Indonesia, khususnya di Purwakarta, menjadi dasar dilakukannya penelitian dimana adanya kelekatan ibu dan janin merupakan salah satu variabel yang dapat mencegah angka kematian ibu hamil. Penelitian ini ingin mengetahui apakah terdapat hubungan antara persepsi dukungan keluarga (perceived family support) terhadap kelekatan ibu dan janin. Penelitian ini dilakukan di Kabupaten Purwakarta dengan mengadaptasi alat ukur Maternal Fetal Attachment dan Perceived Social Support from Family yang kemudian diberikan pada 120 responden. Teknik analisis yang digunakan pada penelitian ini adalah teknik regresi linear dengan program SPSS versi 16.0. Hasil penelitian menunjukkan bahwa terdapat terdapat korelasi yang signifikan pada persepsi dukungan keluarga terhadap kelekatan ibu dan janin $(p<0,01)$ dengan kontribusi sebesar 9 persen. Selain itu, terdapat pula temuan tambahan dari analisis statistik lintas tabulasi data demografi responden terhadap kelekatan ibu dan janin yaitu terdapat pengaruh tingkat pendidikan terhadap kelekatan ibu dan janin. Maka dari itu, penelitian ini menyimpulkan bahwa persepsi dukungan keluarga berpengaruh secara signifikan terhadap kelekatan ibu dan janin, serta pengaruh variabel pendidikan terhadap kelekatan ibu-jann perlu dikaji lebih lanjut.
\end{abstract}

Kata Kunci: kelekatan ibu dan janin; persepsi dukungan keluarga; Angka Kematian Ibu (AKI); Purwakarta

\begin{abstract}
This study is a non-experimental quantitative study using correlational research method. The high prevalence of maternal mortality rate (AKI) in Indonesia, particularly in Purwakarta is the basis of this research where maternal attachment is variables that can prevent the high rates of AKI. The purposes of this study is to find out is there a relationship between perceived family support towards maternal fetal attachment. This study was conducted in Purwakarta by adopting the Maternal Fetal Attachment Scale and Peceived Social Support from Family to 120 research subjects. The analysis technique in this study is linear regression technique with SPSS version 16.0 program. The results showed that there was a relationship between perceived family support towards maternal fetal attachment with 9 percent contribution. In addition, there are additional findings from the statistical analysis of cross-tabulated demographic data of the subject of research that there is the effect of education level to maternal fetal attachment. This study concludes that perceived family support is signifacntly correlated with maternal fetal attachment and the correlation of educational level towards maternal fetal attachment still need to be studied further.
\end{abstract}

Keywords: maternal-fetal attachment; perceived family support; maternal mortality rate (AKI); Purwakarta 


\section{PENDAHULUAN}

Kelekatan ibu dan janin adalah ikatan afeksional yang terus berkembang antara ibu dan janinnya (Adamson-Macedo 2005 dalam Hassan \& Hassan, 2017). Hal ini merupakan bagian penting dari proses kehamilan karena dapat meningkatkan kualitas kehamilan dan kualitas kelekatan ibu dan anak pasca-melahirkan (Alhusen, 2008; Maddahi, Dolatian, Khoramabadi, \& Talebi, 2016). Kelekatan ibu dan janin dapat memberi dampak positif bagi kehamilan, sehingga dapat menurunkan tingkat kematian ibu maupun tingkat kematian bayi. Pasalnya, fenomena yang muncul menunjukkan bahwa Indonesia menempati urutan tertinggi ketiga di ASEAN untuk kasus Angka Kematian Ibu (AKI) (sumber: Depkes.go.id). Dari data tersebut, salah satu kota dengan angka AKI yang cukup tinggi adalah Purwakarta, yakni terdapat 50 kasus AKI di Purwakarta pada tahun 2016 (Dinas Kesehatan Provinsi Jawa Barat, 2016). Berkaitan dengan hal tersebut, kelekatan ibu dan janin dapat menjadi isu penting yang sangat berpengaruh pada praktik kesehatan yang kemudian dapat berdampak pada kesehatan dan kesejahteraan ibu hamil dan janin yang akan dilahirkan.

Dalam membahas kelekatan ibu dan janin secara konseptual, Cranley (1993) membagi kelekatan ibu dan janin ke dalam beberapa dimensi, yaitu kognitif (differentiation of self from the fetus, attributing characteristics, and intention to the fetus), emosional (giving of self), dan perilaku (interaction with the fetus and role taking). Ketiga dimensi tersebut kemudian digunakan oleh Cranley (1981) untuk mengembangkan alat ukur Maternal Fetal Attachment Scale (Doan \& Zimerman, 2008). Aspek kognitif (differentiation of self from the fetus, attributing characteristics, and intention to the fetus) merupakan kemampuan ibu dalam mengonseptualisasikan janin sebagai individu selama ia hamil (Doan \& Zimerman, 2008). Hal ini dapat dilihat ketika ibu berpikir apakah janinnya merasa sempit di dalam perutnya atau tidak. Pemikiran tersebut menunjukkan adanya kemampuan kognitif ibu dalam menilai janin sebagai individu yang berbeda dengan dirinya (Koniak-griffin 1988 dalam Hassan \& Hassan, 2017). Aspek emosional (giving of self) merupakan empati dan emosi yang berkembang pada diri wanita terhadap janin (Doan \& Zimerman, 2008). Aspek ini dapat dilihat ketika ibu berkenan untuk menghadapi setiap masalah kehamilan demi kebaikan janinnya. Perilaku tersebut menunjukkan bahwa terdapat empati dan emosi ibu untuk janin yang ada di dalam dirinya (Kohan \& Salehi, 2017). Aspek perilaku (interaction with the fetus and role taking) merupakan perilaku yang muncul pada ibu hamil karena keberadaan janin dalam dirinya (Doan \& Zimerman, 2008). Perilaku tersebut dapat berupa praktik kesehatan atau adanya interaksi yang berkembang antara ibu dan janin (Doan \& Zimerman, 2008).

Salah satu variabel psikologis yang memiliki hubungan inkonsistensi dengan kelekatan ibu dan janin adalah persepsi dukungan keluarga (perceived family support) yang dapat didefinisikan sebagai keyakinan individu bahwa keluarga dapat memenuhi kebutuhannya akan dukungan, informasi, dan sebaliknya (Procidano \& Heller, 1983). Terdapat banyak penelitian yang menemukan bahwa persepsi dukungan keluarga berdampak baik pada kelekatan ibu dan janin, Persepsi dukungan sosial khususnya dari keluarga memiliki hubungan yang signifikan dengan kelekatan ibu-janin. Hal tersebut dibuktikan pada penelitian Abdollahpour, Ramezani, dan Khosravi (2015) menyatakan bahwa persepsi dukungan keluarga memiliki hubungan yang signifikan dengan kehamilan dan memberi dampak samping pada kelahiran dan kesehatan ibu dan bayi. Oleh karenanya perasaan ibu tentang bayinya akan sangat tergantung pada dukungan yang dia dapatkan dari suami, kerabat, dan orang sekitar (Rowan 2006 dalam Juariah, 2018).

Di sisi lain, pada penelitian Koniak-griffin (1988) dalam Hassan \& Hassan (2017), menyatakan bahwa di Amerika, persepsi dukungan sosial termasuk di dalamnya keluarga, memiliki korelasi yang tidak signifikan dengan kelekatan ibu dan janin. Hal tersebut sejalan dengan penelitian Mercer, Ferketich, May, DeJoseph, \& Sollid (1988) yang juga dilakukan di Amerika, menemukan bahwa tidak ada hubungan yang terlalu signifikan antara persepsi dukungan keluarga dengan kelekatan ibu dan janin. Dalam hal ini, Hassan \& Hassan, (2017) menyatakan bahwa inkonsistensi penelitian tersebut dikarenakan perbedaan konteks kehamilan secara budaya dan perbedaan tempat dilaksanakannya penelitian. Meskipun demikian, mayoritas penelitian menemukan bahwa kelekatan ibu janin dan persepsi dukungan keluarga di Amerika memiliki hubungan yang signifikan, sementara penelitian yang dilakukan oleh Hassan \& Hassan (2017) di Mesir menemukan bahwa persepsi 
dukungan keluarga tidak berpengaruh secara signifikan terhadap kelekatan ibu dan janin. Dalam hal ini, Mesir memang tidak melihat kehamilan sebagai suatu proses yang istimewa, sehingga dukungan yang diberikan juga tidak signifikan. Namun, meskipun ibu hamil tidak mendapatkan dukungan yang signifikan, kelekatan ibu-janin di Mesir tetap tinggi. Karenanya, rendahnya persepsi dukungan keluarga hal tidak membuat kelekatan ibu dan janin di Mesir menjadi rendah (Hassan \& Hassan, 2017). Hal ini dikuatkan oleh penelitian Jirka, Schuett, \& Foxall (1996) yang juga menyatakan bahwa kehamilan tidak menentukan besarnya dukungan sosial yang ia terima, sehingga tidak ada hubungan yang signifikan antara persepsi dukungan keluarga serta kelekatan ibu dan janin (Jirka dkk., 1996). Sebagai tambahan, perlu diketahui bahwa persepsi dukungan sosial merupakan keyakinan individu bahwa kebutuhannya akan dukungan terpenuhi, sementara makna dukungan sosial di setiap budaya berbeda-beda (Hassan \& Hassan, 2017). Azimi, Fahami, Soheila \& Mohamadirizi (2018) menyebutkan bahwa tingkat persepsi dukungan sosial dipengaruhi oleh respondentivitas individu terhadap dukungan sosial ia dapatkan. Oleh karenanya, hal ini juga menjadi penyebab hubungan persepsi dukungan keluarga dan kelekatan ibu dan janin menjadi inkonsisten (Azimi dkk., 2018).

Indonesia merupakan salah satu negara dengan budaya yang kental termasuk dalam memaknai kehamilan. Penanaman nilai bagi ibu hamil dan janin dapat dilihat melalui beberapa pantangan yang ada di berbagai daerah dengan maknanya yang berbeda-beda. Misalnya di daerah Banjar, ibu hamil dilarang duduk di depan pintu dan meletakkan sisir di atas kepala karena diyakini dapat menyebabkan kesulitan saat proses melahirkan (Sari, Husaini, \& Ilmi, 2017). Pada masyarakat Baduy di Kabupaten Lebak, ritual yang dilakukan pada masa kehamilan adalah ngaragap beuteung, yaitu memijat bagian perut yang disertai dengan jampi-jampi untuk meminta keselamatan ibu dan janin (Kartika, Agustiya, \& Kusnali, 2019).

Selain kedua daerah tersebut, terdapat pula daerah yang memiliki banyak tantangan perihal ibu hamil, yaitu Purwakarta. Daerah ini merupakan kabupaten dengan suku asli Sunda. Dalam budaya Sunda di Purwakarta, ibu hamil dilarang melihat sesuatu yang menjijikkan, melihat orang cacat, menjenguk orang sakit dan meninggal, serta berziarah ke kuburan. Pada usia tiga bulan kandungan, ibu hamil dilarang turun ke sungai, melakukan pemandian, keluar di malam hari, duduk tanpa bantal, memakan buah-buahan bekas kelelawar, mengisi kasur dan bantal dengan kapuk, bahkan tidak boleh menyembelih, menyakiti, atau memburu hewan. Selain itu, terdapat gejala alam yang perlu diperhatikan ibu hamil selama masa kehamilannya, seperti gerhana bulan, gerhana matahari, atau gempa bumi (Rusnandar, Sulastri, \& Achdiani, 2017). Masyarakat Sunda meyakini bahwa gejala alam memiliki arti tersendiri, seperti ketika ibu hamil dan pasangannya sedang bermasalah, maka di antara keduanya wajib menjauhkan diri untuk sementara agar mendapat ketenangan (Rusnandar dkk., 2017).

Pada dasarnya, makna inti dari seluruh rangkaian upacara dan pantangan bagi ibu hamil dalam masyarakat Sunda adalah agar seorang perempuan harus selalu menjaga kehamilannya. Hal ini merupakan dasar pemikiran masyarakat Sunda tentang kehamilan. Kehamilan dianggap sebagai sesuatu yang sangat penting dan harus dijaga. Terdapat keyakinan bahwa jika pantangan itu dilanggar akan mengakibatkan hal buruk pada ibu dan bayi yang dikandungnya (Juariah, 2018). Selain itu, masyarakat Sunda juga memandang bahwa selama masa kehamilan, pasangan dan keluarga harus mendukung dan menciptakan lingkungan yang menyenangkan agar proses persalinan dapat dilalui dengan baik (Rusnandar dkk., 2017). Bentuk keterlibatan suami dapat berupa kepatuhan dalam mengikuti keharusan dan pantangan, serta keyakinan akan akibat jika kebiasaan tersebut tidak diikuti (Juariah, 2018).

Temuan beberapa penelitian sebelumnya terkait inkonsistensi hubungan antara persepsi dukungan keluarga dengan kelekatan ibu dan janin, salah satunya dapat disebabkan oleh tempat penelitian. Oleh karena itu, peneliti ingin membuktikkan bagaimana hubungan persepsi dukungan keluarga terhadap kelekatan ibu dan janin di Purwakarta yang kental dengan budaya Sunda seperti yang telah dijeaskan, sehingga hipotesis penelitian ini adalah terdapat hubungan yang signifikan antara persepsi dukungan keluarga terhadap kelekatan ibu dan janin. Manfaat teoritis dari penelitian ini adalah mengetahui seberapa besar kontribusi persepsi dukungan keluarga terhadap kelekatan ibu dengan janinnya (MFA). Adapun manfaat praktis dari penelitian ini adalah membantu menjadi rujukan ilmiah untuk mengantisipasi fenomena angka AKI 
yang tinggi di Indonesia, khususnya di Purwakarta.

\section{METODE}

Penelitian ini merupakan penelitian kuantitatif dengan jenis penelitian non-eksperimental dan metode korelasional. Teknik pengambilan sampel yang digunakan pada penelitian ini adalah convenience sampling dengan mengakses lingkungan yang tersedia dan dapat diakses oleh peneliti (Kerlinger \& Lee, 2000). Peneliti akan menyebarkan kuesioner secara luring dan daring pada ruang obrolan (group chat) ibu hamil di Purwakarta. Selain itu, peneliti juga menyebarkan kuesioner secara daring kepada relasi yang dimiliki oleh peneliti. Jumlah responden ini sebesar $120 \mathrm{ibu}$ hamil yang tinggal di Purwakarta.

Alat ukur yang digunakan adalah hasil adaptasi dari Perceived Family Support from Family (PssFa) yang dikembangkan oleh Procidano \& Heller (1983) dan Maternal Fetal Attachment Scale (MFAS) yang dikembangkan oleh Cranley (1981) dengan menggunakan petunjuk adaptasi alat ukur dari Beaton, Claire, Guillemin, \& Ferraz (2000). Acuan tersebut digunakan karena petunjuk adaptasi pada artikel tersebut berdasarkan ulasan terhadap adapatasi lintas budaya dalam bidang medis, sosiologi, dan psikologi (Beaton dkk., 2000). Pss-Fa terdiri dari 20 butir pernyataan dengan 5 respons jawaban yang berbentuk skala likert dalam rentan 1 sampai 5. Rentang skor total Pss-Fa adalah 0-100 dengan interpretasi bahwa semakin tinggi jumlah skor menunjukkan semakin tinggi pula persepsi dukungan keluarga dalam diri individu. Adapun MFAS terdiri dari 24 butir pernyataan dengan 7 respons jawaban yang berbentuk skala likert dengan rentang 1 sampai 7 . 1 untuk tidak pernah dan 7 untuk selalu. Rentang skor MFAS adalah 1-168 dengan interpretasi bahwa semakin tinggi jumlah skor yang didapatkan maka semakin lekat hubungan ibu dengan janinnya. Skala respons kedua alat ukur tidak disamakan karena pada alat ukur Pss-Fa, skala likert 1-5 digunakan untuk meminimalisir terjadinya informasi yang hilang atau kurang (loss of information) dan untuk melakukan analisis statistik parametrik (Glozah \& Pevalin, 2017), sementara pada alat ukur MFAS yang digunakan merupakan MFAS yang telah diadaptasi ke versi Jerman dan ditemukan bahwa MFAS versi Jerman dengan skala Likert 1-7 dianggap reliabel dan dapat mengukur ikatan ibu dan janin (Doster dkk., 2018).
Uji validitas dari hasil adaptasi kedua alat ukur tersebut diujikan pada $30 \mathrm{ibu}$ hamil (Field, 2005) di Purwakarta dan didapatkan nilai Alpha Cronbach Pss-Fa sebesar 0,70 dan MFAS sebesar 0,82 . Berdasarkan batas kriteria reliabilitas Nunnaly dan Bernstein (1994), maka diketahui bahwa adaptasi dari kedua alat ukur tersebut dapat dikatakan reliabel karena memiliki nilai di atas 0,7. Teknik analisis data yang digunakan adalah analisis regresi dengan SPSS versi 22.0. Teknik regresi linear digunakan untuk mengetahui apakah terdapat kontribusi persepsi dukungan keluarga terhadap kelekatan ibu dan janin.

\section{HASIL DAN PEMBAHASAN}

\section{Hasil Analisis Demografi Responden}

Pada penelitian ini, terdapat 35 responden yang mengisi kuesioner secara daring dan 85 responden yang mengisi kuesioner secara luring. Berikut data demografi responden dalam Tabel 1 . Berdasarkan tabel di atas maka dapat diketahui bahwa dari 120 responden, mayoritas responden berusia 20 sampai 25 tahun $(M=2,9, S D=1,19)$ dengan rata-rata tingkat pendidikan SMA/Sederajat $\quad(M=2,9, \quad S D=0,6)$, tingkat penghasilan di atas Rp 2.000.000 (M=3,0, $S D=0,9)$, dan mengalami kehamilan anak pertama $(M=, \quad S D=0,9)$. Oleh karenanya, dapat disimpulkan bahwa mayoritas responden merupakan pemudi dengan tingkat pendidikan rendah dan telah memiliki pengalaman melahirkan.

\section{Tabel 1. Analisis Demografi Responden}

\begin{tabular}{lllc} 
Usia & Jumlah & Presentase \\
\hline 1 & $15-20$ tahun & 9 & $7,5 \%$ \\
\hline 2 & $20-25$ tahun & 39 & $32,5 \%$ \\
\hline 3 & $25-30$ tahun & 36 & $30 \%$ \\
\hline 4 & $30-35$ tahun & 16 & $13,3 \%$ \\
\hline 5 & $>35$ tahun & 20 & $16,7 \%$ \\
\hline \multicolumn{2}{l}{ Tingkat Pendidikan } & & \\
\hline 1 & SD/Sederajat & 4 & $3,3 \%$ \\
\hline 2 & SMP/Sederajat & 21 & $17,7 \%$ \\
\hline 3 & SMA/Sederajat & 76 & $63,3 \%$ \\
\hline 4 & $>$ SMA/Sederajat & 19 & $15,8 \%$ \\
\hline \multicolumn{1}{l}{ Tingkat Penghasilan } & & \\
\hline 1 & $0-500.000$ & 10 & $8,3 \%$ \\
\hline 2 & $500.000-1.000 .000$ & 29 & $24,2 \%$ \\
\hline 3 & $1.000 .000-2.000 .000$ & 32 & $26,7 \%$ \\
\hline 4 & $>2.000 .000$ & 49 & $40,8 \%$ \\
\hline Kehamilan Anak Ke & & $30 \%$ \\
\hline 1 & Belum pernah melahirkan & 36 & $35 \%$ \\
\hline 2 & $1 \mathrm{x}$ & 42 & $25,8 \%$ \\
\hline 3 & $2 \mathrm{x}$ & 31 & $9,2 \%$
\end{tabular}

\section{Hasil Analisis Persepsi Dukungan Keluarga}

Berikut hasil skor persepsi dukungan keluarga dari 120 responden yang terdapat di Tabel 2 . 
Diketahui bahwa rata-rata responden memliki persepsi dukungan keluarga yang "tinggi". Artinya, rata-rata responden merasa bahwa ia didukung oleh keluarganya dengan baik. Selain itu, diketahui bahwa terdapat responden yang memliki persepsi dukungan keluarga yang rendah. Namun, secara umum dapat dikategorikan bahwa seluruh responden memiliki persepsi dukungan keluarga yang bervariasi, namun tidak ada responden yang memiliki persepsi dukungan keluarga yang sangat rendah.

Tabel 2. Analisis Statistik Persepsi Dukungan Keluarga

\begin{tabular}{lccc}
\hline Pss-Fa & $\begin{array}{c}\text { Skor } \\
\text { Total }\end{array}$ & $\begin{array}{c}\text { Skor rata- } \\
\text { rata }\end{array}$ & Label \\
\hline Mean & 75 & 4 & 4 \\
Minimum & 36 & 2 & 2 \\
Maximum & 96 & 5 & 5 \\
\hline
\end{tabular}

Hasil Analisis Kelekatan Ibu dan Janin

Berikut hasil skor kelekatan ibu dan janin dari 120 responden yang terdapat di Tabel 3. Diketahui bahwa rata-rata responden memliki persepsi dukungan keluarga yang "lekat" denga janinnya. Artinya, rata-rata responden memiliki kelekatan yang baik dengan janinnnya. Selain itu, diketahui bahwa responden yang kelekatan ibu dan janinnya paling rendah pun merasa bahwa ia cukup lekat dengan janinnya. Berdasarkan hasil ini, maka diketahui bahwa tidak ada responden yang memiliki kelekatan ibu janin yang rendah, sehingga dapat dikategorikan bahwa seluruh responden memiliki kelekatan ibu dan janin yang baik.

Tabel 3. Analisis Statistik Persepsi Dukungan Keluarga

\begin{tabular}{lccc}
\hline MFAS & $\begin{array}{c}\text { Skor } \\
\text { Total }\end{array}$ & $\begin{array}{c}\text { Skor } \\
\text { rata-rata }\end{array}$ & Label \\
\hline Mean & 132 & 5 & 6 \\
Minimum & 83 & 4 & 4 \\
Maximum & 168 & 7 & 7 \\
\hline
\end{tabular}

Hasil Regresi Persepsi Dukungan Keluarga terhadap Kelekatan Ibu dan janin

Berikut hasil analisis statistik regresi persepsi dukungan keluarga terhadap kelekatan ibu dan janin yang tercantum dalam Tabel 4. Dapat diketahui bahwa hipotesis penulis terbukti, yaitu terdapat hubungan persepsi dukungan keluarga terhadap kelekatan ibu dan janin $(p<0,005)$. Adapun kontribusi persepsi dukungan keluarga terhadap kelekatan ibu dan janin sebesar 9 persen, maka dapat diketahui bahwa kontribusi persepsi dukungan keluarga terhadap kelekatan ibu dan janin tidak terlalu besar, namun tetap memberikan kontribusi terhadap kelekatan ibu dan janin. Dengan kata lain, kurangnya persepsi dukungan keluarga akan memberikan pengaruh negatif terhadap kelekatan ibu dan janin. Temuan pada penelitian ini sejalan dengan penelitian lain yang menemukan adanya hubungan antara persepsi dukungan keluarga terhadap kelekatan ibu dan janin (Chang, Chen, \& Chen, 2016; Delavari, 2017; Hassan \& Hassan; 2018). Maka, temuan penelitian Mercer dkk. (1988) dan Jirka dkk., (1996) tidak sejalan dengan penelitian ini. Penulis menduga bahwa salah satu penyebab inkonsistensi temuan penelitian adalah adanya faktor budaya, seperti yang dinyatakan Hassan \& Hassan (2018).

Tabel 4. Hasil Regresi Persepsi Dukungan Keluarga Terhadap Kelekatan Ibu dan Janin

\begin{tabular}{lccccc}
\hline \multicolumn{1}{c}{ Variabel } & R Square & F & Beta & Nilai-t & Sig \\
\hline $\begin{array}{l}\text { Persepsi } \\
\text { dukungan } \\
\text { keluarga }\end{array}$ & 0,9 & 11,09 & 0,29 & 3,33 & 0,001 \\
\hline
\end{tabular}

Secara budaya, Indonesia merupakan negara dengan budaya kolektivis yang mengutamakan nilai kebersamaan, sehingga dukungan dan penerimaan oleh lingkungan menjadi penting bagi individu. Budaya Sunda menilai kehidupan sosial sebagai nilai luhur yang patut di junjung sehingga orang Sunda cenderung mengedepankan lingkungan sosial sebagai hal utama dalam diri individu (Rahman, Sarbini, Tarsono, Fitriah, Mulayana, 2018). Selain itu, budaya Sunda juga menilai kehamilan sebagai sesuatu yang penting dan dukungan akan kehamilan tersebut merupakan suatu norma dalam keluarga. Oleh karenanya, tentu persepsi dukungan keluarga berpengaruh secara signifikan terhadap kelekatan ibu dan janin.

Tidak hanya jenis masyarakat kolektivis atau individualis yang berperan, tetapi juga bagaimana lingkungan keluarganya memaknakan konsep dukungan sosial dan kehamilan. Oleh karena itu, salah satu penyebab adanya inkonsistensi penelitian pengaruh persepsi dukungan keluarga terhadap kelekatan ibu dan janin adalah faktor sosial tempat penelitian tersebut dilaksanakan. Kesimpulan ini sejalan dengan pernyataan (Andrek, Kekecs, Hadhazi, Boukydis, \& Varga, 2016) bahwa perbedaan kultur sangat berpengaruh 
terhadap variabel prediktor kelekatan ibu dan janin.

Analisis Lanjutan: Analisis Lintas Tabulasi Demografi Responden terhadap Kelekatan Ibu dan janin

Berikut disampaikan hasil analisis statistik lintas tabulasi demografi responden terhadap kelekatan ibu dan janin dalam Tabel 5. Dapat diketahui bahwa data demografi yang berpengaruh secara terhadap kelekatan ibu dan janin di Purwakarta adalah tingkat penghasilan $(p<0,005)$, sementara yang lainnya tidak $((p>0,005)$. Temuan penelitian ini sejalan dengan peneltian yang dilakukan oleh Eichler, Schmidt, Hiemisch, Kiess, \& Hilbert (2019) yang menyatakan bahwa Status Ekonomi dan Sosial (SES) yang rendah berhubungan dengan kelekatan ibu dan janin. Namun, Eichler dkk., (2019) tidak menyatakan secara spesifik jenis SES rendah apa yang berpengaruh pada kelekatan ibu dan janin. Penelitian ini yang memiliki responden penelitian rata-rata tingkat pendidikan SMA/sederajat menyatakan bahwa tingkat pendidikan yang rendah berpengaruh terhadap kelekatan ibu dan janin. Dengan demikian, perlu ada penelitian lebih lanjut mengenai prediktor kelekatan ibu dan janin yang sesuai dengan nilai budaya Indonesia supaya dapat digambarkan dengan lebih jelas seperti apa faktor risiko dan faktor protektif kelekatan ibu dan janin agar angka AKI dapat ditekan.

Tabel 5. Hasil Lintas Tabulasi Data Demografi Responden Terhadap Kelekatan Ibu dan Janin

\begin{tabular}{lcc}
\hline Variabel & $\begin{array}{c}\text { Pearson Chi } \\
\text { Square }\end{array}$ & $\begin{array}{c}\text { Asymp. Sig } \\
\text { (2 Sided) }\end{array}$ \\
\hline Tingkat Pendidikan & 210,033 & 0,001 \\
Usia & 175,543 & 0,768 \\
Penghasilan & 153,915 & 0,216 \\
Kehamilan anak ke- & 147,693 & 0,333 \\
\hline
\end{tabular}

Adapun analisis lanjutan yang dilakukan oleh peneliti merupakan suatu pendekatan tambahan di luar masalah penelitian untuk melihat apakah faktor SES berupa rendahnya tingkat pendidikan dan kemiskinan dapat berpengaruh terhadap kelekatan ibu dan janin. Ternyata, ditemukan hasil bahwa keduanya tidak berpengaruh pada kelekatan ibu dan janin. Selain itu, pada analisis lanjutan pengaruh usia ibu sebagai salah satu faktor, juga tidak berpengaruh secara signifikan terhadap kelekatan ibu dan janin. Temuan analisis lanjutan ini tidak sejalan dengan penelitian
Hassan dan Hassan (2017) yang secara jelas menyatakan bahwa usia ibu, tingkat pendidikan, dan latar belakang keluarga merupakan faktor demografi yang berpengaruh secara signifikan terhadap kelekatan ibu dan janin.

Pada penelitian ini responden dengan pendapatan keluarganya di bawah Upah Mininum Kota/Kabupaten (UMK), usia ibu yang relatif muda, dan tingkat pendidikan hanya maksimal SMA/sederajat memiliki tingkat kelekatan ibu dan janin yang baik. Hal ini menunjukkan bahwa responden tidak bergantung pada ketersediaan fasilitas, jenjang pendidikan, maupun usia. Peneliti menduga justru ini berkaitan juga dengan karakteristik budaya Sunda yang mengedepankan kualitas hubungan sosial dan individu daripada sesuatu yang berada di luar individu, seperti adanya ketersediaan fasilitas yang mapan. Selain itu, pemaknaan tentang kehamilan dan dukungan sosial bagi ibu hamil yang sangat kental dalam budaya sunda juga membiaskan pengaruh faktor demografis responden terhadap kelekatan ibu dan janin.

Faktor budaya yang begitu kuat hingga dapat membiaskan faktor demografis, merupakan bukti bahwa budaya memainkan peranan yang sangat penting dalam psikologi manusia (Jack, Crivelli, \& Whaetley, 2018). Budaya merupakan sistem koheren yang mencakup praktik, keyakinan, dan nilai yang diciptakan oleh suatu masyarakat dan dibagikan dari generasi ke generasi (Causadias, Vitriol, \& Atkin, 2018). Oleha karenanya, perbedaan budaya dapat membuat perspektif psikologi perkembangan kurang kaya dalam melihat suatu gejala psikologis (Causadias, Vitriol, \& Atkin, 2018). Pengakuan terhadap adanya bias dalam misatribusi budaya menuntut perubahan dalam psikologi perkembangan (Causadias, Vitriol, \& Atkin, 2018). Berdasarkan hasil tersebut, keterbatasan penelitian ini adalah tidak menjadikan faktor budaya sebagai variabel yang diteliti. Penulis menyarankan untuk memasukkan variabel budaya sebagai variabel yang diteliti, baik sebagai pilot study, maupun bagian utama dari penelitian. Hal ini ditujukan agar temuan penelitian lebih komprehensif dalam melihat gejala psikologi yang diteliti, khususnya berkaitan dengan kelekatan ibu dan janin.

\section{SIMPULAN}

Berdasarkan hasil temuan pada penelitian ini, dapat disimpulkan bahwa terdapat hubungan antara persepsi dukungan keluarga dengan 
kelekatan ibu dan janin dengan kontribusi sebesar 9 persen. Selain itu, temuan tambahan dari penelitian ini adalah bahwa tingkat pendidikan berpengaruh terhadap kelekatan ibu dan janin, sehingga mungkin terdapat kontribusi dari variabel lain yang berkontribusi lebih besar pada kelekatan ibu dan janin selain persepsi dukungan keluarga dan tingkat pendidikan. Hal tersebut dapat menjadi celah bagi penelitian berikutnya untuk mengetahui variabel apa saja yang berpengaruh pada kelekatan ibu dan janin, sehingga pengetahuan dan studi mengenai kelekatan ibu dan janin dapat bertambah dan fenomena Angka Kematian Ibu (AKI) pun dapat dicegah dan diketahui cara mengatasinya.

Keterbatasan penelitian ini adalah jumlah sampel yang sedikit dan kontrol terhadap responden yang hanya berdasarkan tempat tinggal saja. Oleh karenanya, peneliti menyarankan penelitian berikutnya memperbanyak jumlah sampel dan memberika kriteria responden yang lebih spesifik agar temuan penelitian tentang kelekatan ibu dan janin menjadi lebih kaya.

\section{UCAPAN TERIMA KASIH}

Penulis ucapkan terima kasih yang sebesarbesarnya kepada suami, keluarga, dan segenap tim pengajar di Universitas Indonesia yang selalu mendukung penelitian ini. Tanpa dukungan dari mereka, mungkin penulis tidak dapat menyelesaikan penelitian ini.

\section{DAFTAR PUSTAKA}

Abdollahpour, S., Ramezani, S., \& Khosravi, A. (2015). Perceived social support among family in pregnant women. International Journal of Pediatrics, 3(5), 879-888. https://doi.org/10.22038/ijp.2015.4703

Alhusen, J. L. (2008). A literature update on maternal-fetal attachment. JOGNN - Journal of Obstetric, Gynecologic, and Neonatal Nursing, 37(3), 315-328. https://doi.org/10.1111/j.15526909.2008.00241.x

Andrek, A., Kekecs, Z., Hadhazi, E., Boukydis, Z., \& Varga, K. (2016). Re-Evaluation of the Psychometric Properties of the MaternalFetal Attachment Scale in a Hungarian Sample. JOGNN - Journal of Obstetric, Gynecologic, and Neonatal Nursing, 45(5), e15-e25. https://doi.org/10.1016/j.jogn.2016.05.005
Azimi, M., Fahami, F., Soheila, \& Mohamadirizi. (2018). The Relationship Between Perceived Social Support in The First Pregnancy and Fear of Childbirth. Iranian Journal of Nursing and Midwifery Research, 23(3), 235-239. https://doi.org/10.4103/ijnmr.IJNMR_170_1 6

Beaton, D. E., Claire, B., Guillemin, F., \& Ferraz, M. B. (2000). Guidelines for The Process of Cross-Cultural Adaptation of Self-report Measures. Spine, 25(24), 3186-3191. https://doi.org/10.1097/00007632200012150-00014

Causadias, J. M., Vitriol, J. A., \& Atkin, A. L. (2018). The cultural (mis)attribution bias in developmental psychology in the United States. Journal of Applied Developmental Psychology, 59(September 2017), 65-74. https://doi.org/10.1016/j.appdev.2018.01.00 3

Cranley, M. S. (1993). The Origins of the MotherChild Relationship-A Review. Physical \& Occupational Therapy in Pediatrics, $12(2-$ 3), 39-51. https://doi.org/10.1080/J006v12n02_03

Dinas Kesehatan Provinsi Jawa Barat. (2016). Profil Kesehatan. Profil Kesehatan Provinsi Jawa Barat, 179.

Doster, A., Wallwiener, S., Müller, M., Matthies, L. M., Plewniok, K., Feller, S., Kuon, R. J., Sohn, C., Rom, J., Wallwiener, M., \& Reck, C. (2018). Reliability and validity of the German version of the Maternal-Fetal Attachment Scale. Archives of Gynecology and Obstetrics, 297(5), 1157-1167. https://doi.org/10.1007/s00404-018-4676-x

Eichler, J., Schmidt, R., Hiemisch, A., Kiess, W., \& Hilbert, A. (2019). Gestational weight gain, physical activity, sleep problems, substance use, and food intake as proximal risk factors of stress and depressive symptoms during pregnancy. $B M C$ Pregnancy and Childbirth, 19(1), 1-14. https://doi.org/10.1186/s12884-019-2328-1

Field, A. (2005). Discovering Statistics Using Spss Third Edition. In Sage (Vol. 2nd, Issue Third Edition). https://doi.org/10.1016/j.landurbplan.2008.0 6.008

Glozah, F. N., \& Pevalin, D. J. (2017). Psychometric Properties of the Perceived Social Support from Family and Friends Scale: Data from an Adolescent Sample in 
Ghana. Journal of Child and Family Studies, 26(1), 88-100. https://doi.org/10.1007/s10826-016-0535-1

H.Doan; A. Zimerman. (2008). Prenatal Attachment: A Developmental Model. 20(1), 20-28. http://www.mattes.de/buecher/praenatale_ps ychologie/PP_PDF/PP_20_12_Doan_Zimerman.pdf

Hassan, N. M. M., \& Hassan, F. M. A. E. (2017). Predictors of Maternal Fetal Attachment among Pregnant Women. IOSR Journal of Nursing and Health Science, 6(1), 95-106. https://doi.org/10.9790/1959-06010695106

Jack, R. E., Crivelli, C., \& Wheatley, T. (2018). Data-Driven Methods to Diversify Knowledge of Human Psychology. Trends in Cognitive Sciences, 22(1), 1-5. https://doi.org/10.1016/j.tics.2017.10.002

Jirka, J., Schuett, S., \& Foxall, M. J. (1996). Loneliness and social support in infertile couples. Journal of Obstetric, Gynecologic, and Neonatal Nursing: JOGNN / NAACOG, 25(1), 55-60. https://doi.org/10.1111/j.15526909.1996.tb02513.x

Juariah, -. (2018). Kepercayaan Dan Praktik Budaya Pada Masa Kehamilan Masyarakat Desa Karangsari, Kabupaten Garut. Sosiohumaniora, 20(2), 162-167. https://doi.org/10.24198/sosiohumaniora.v20 i2. 10668

Kartika, V., Agustiya, R. I., Kusnali, A., Humaniora, P., Litbangkes, B., \& Kesehatan, K. (2019). Budaya Kehamilan dan Persalinan pada Masyarakat Baduy di Kabupaten Lebak, Tahun 2018. Buletin Penelitian Sistem Kesehatan, 22(3), 192199.

https://doi.org/https://doi.org/10.22435/hsr.v 22i3.1494

Kohan, S., \& Salehi, K. (2017). Maternal-Fetal Attachment: What We Know and What We Need to Know. International Journal of Pregnancy \& Child Birth, 2(5), 146-148. https://doi.org/10.15406/ipcb.2017.02.00038

Koniak-griffin, D. (1988). The relationship between social support, self-esteem, and maternal-fetal attachment in adolescents. Research in Nursing \& Health, 11(4), 269278. https://doi.org/10.1002/nur.4770110408

Maddahi, M. S., Dolatian, M., Khoramabadi, M., \& Talebi, A. (2016). Correlation of maternal-fetal attachment and health practices during pregnancy with neonatal outcomes. Electronic Physician, 8(7), 26392644. https://doi.org/10.19082/2639

Mercer, R. T., Ferketich, S., May, K., DeJoseph, J., \& Sollid, D. (1988). Further exploration of maternal and paternal fetal attachment. Research in Nursing \& Health, 11(2), 8395. https://doi.org/10.1002/nur.4770110204 Nandang Rusnandar, Sulastri, S., \& Achdiani, Y. (2017). PRANATA PENDIDIKAN. Patanjala, 9(1), 31-44. https://doi.org/https://dx.doi.org/10.30959/pa tanjala.v9i1.344

Rahman, A. A., Sarbini, S., Tarsono, T., Fitriah, E. A., \& Mulyana, A. (2018). Studi Eksploratif Mengenai Karakteristik dan Faktor Pembentuk Identitas Etnik Sunda. Jurnal Psikologi Islam Dan Budaya, 1(1), 18. https://doi.org/10.15575/jpib.v1i1.2072

Sari, L. S., Husaini, H., \& Ilmi, B. (2017). Kajian Budaya Dan Makna Simbolis Perilaku Ibu Hamil Dan Ibu Nifas. Jurnal Berkala Kesehatan, 1(2), 78. https://doi.org/10.20527/jbk.v1i2.3146 